French research

\section{All civil servants now}

FRENCH researchers working for the major national research councils are about to receive the pieces of paper that declare them to be civil servants and so guaranteed a job for life, nearly a year after the principle was first agreed by the French National Assembly. The ministry of public administration, it seems, has been fighting a rearguard action to prevent researchers being given too many exceptions to civil service rules, for fear of other civil servants demanding the same conditions, but now finally the battle is over, and last week the research councils published details of the new arrangements.

These new contracts of employment consist "mostly of exceptions", according to the Centre National de la Recherche Scientifique, the major council for basic science. Yet the contracts are "on the whole not as dynamic as we'd have liked", according to Claude Kordon, a researcher with the Institut National de la Santé et de la Recherche Médicale, who has pursued the reform of scientific employment ever since the present socialist government came to power in 1981 .

According to Kordon, one of the main disappointments is with the categorization of technicians, who will be confined to 13 separate categories and career patterns, according to their qualifications. French laboratory technicians are demoralized by the lack of opportunity for initiative and advancement, Kordon believes, and he had been campaigning for merely one or two categories to allow for more movement and promotion. But the ministry had been "completely obstinate".

Among the exceptions, however, are some "positive things" such as a degree of scientific assessment of technicians for promotion, and certain opportunities to shift categories. But these might affect only a small proportion of jobs, as the whole French research system-like that in many other countries - is blocked by a mass of staff recruited in the 1960 s and not due for retirement for at least a decade.

As for researchers themselves, they will now be divided into two classes (chargés and directeurs de la recherche) as opposed to the present three (attachés, chargés and directeurs), to match a similar change in the categorization of university researchers. Previousiy, all researchers were on rolling three (or more) year contracts, which could in principle be revoked (for example if the Centre National de la Recherche Scientifique pulled out of a line of research) but in practice never were (except for gross misconduct). Now the jobs are officially for life. Even if the French research councils were abolished tomorrow, the state would have to pay its researchers and technicians their salaries and pensions to their deaths.

To the security-conscious French, this could be a passport to greater mobility,
Kordon believes-and mobility is certainly something French research lacks. It is also encouraged by elements in the new contracts that offer bonuses for researchers who change geographical location or subject of research.

In the final analysis, however, the new contracts may prove to be little more than paper, leaving the status quo intact until the great retirement of the $1990 \mathrm{~s}$. More important may be the introduction of a

three-year PhD degree, which will begin in earnest this October, and supplant the present one-year diploma of advanced study (DEA), "third-cycle" two-year thesis and a "state thesis" often not completed before the age of 30 . The existing system frequently tied researchers down to working in the same laboratory for upwards of a decade in what might be the most productive years of their lives. A three-year $\mathrm{PhD}$, followed by a search for jobs, might loosen the French system considerably. But not, of course, until 1988, when the first French PhDs will begin to emerge.

Robert Walgate

\title{
AIDS tests alarm blood banks
}

\section{Washington}

THE American Association of Blood Banks (AABB), while acknowledging great uncertainties in the tests now being developed to screen blood for AIDS (acquired immune deficiency syndrome) antibody, has recommended that all bloodbanks use the tests on every unit of blood collected and that donors whose blood tests positive be informed of the results.

A number of blood bank officials have expressed serious reservations about using the tests because of the high false-positive rates reported in initial trial runs (see Nature 13 December 1984, p. 583). In addition, little is known of the clinical significance of a positive result; it is possible that many with antibody to the AIDS virus, HTLV-III, may never contract the disease. The AABB recommendation notes that "only after several years of experience, along with appropriate epidemiological studies, will there be sufficient information to assess the meaning of a positive test for antibodies to HTLV-III'.

According to $\mathbf{A A B B}$, because of the false-positive problem, the Food and Drug Administration, which must approve any test before it is put to routine use, is planning to require that some kind of confirmatory test be run on all positive samples. The most likely such test would be a Western blot, according to $\mathbf{A A B B}$ and blood-bank officials.

FDA approval of the first test kits is expected shortly.

Although the $\mathbf{A A B B}$ recommendation is not binding on its membership (which includes 2,400 hospital and community blood banks in the United States), its standards are widely followed throughout the world. Stephen Budiansky

\section{Home science seems best}

NORTH Korea must bring its science and technology up to world level, says a leading political monthly, Kulloja. In particular, technical education must be improved, including "teaching the science and technology of other countries in accordance with the specific situation" in North Korea.

This last proviso has apparently caused certain problems. Although the article is signed by a certain Pak Yong Ghol, its somewhat confused and inconsistent argument suggests joint authorship and/or subsequent ideological revision. Several paragraphs extol the burgeoning of science elsewhere. The article nevertheless concludes that such achievements must be studied " only for the purpose of enabling us to know what we have that is better and in order more properly to carry out revolution and construction"'.

In effect, the only practical goals of the proposed drive are fairly mundane and include a non-specific exhortation that science and technology must be used to solve the "problems concerning the Chucheization of the country", which is a reference to reconstruction according to the Chuche variant of socialism favoured by the Party leader, Kim Il-sung.

The tenor of the article, that foreign science and technology, however advanced, "cannot readily fit the situation in our country" appears, at first glance, simply a repetition of the truism that for a developing country, middle technology is more appropriate than advanced. (So why devote so much space to the sophisticated developments which find practical application elsewhere?) In the context of North Korea, the concept seems to have considerable political overtones. Koreans, it is implied, can study best in Korea.

Last month, this proposition was expounded in the somewhat unlikely setting of an international conference of journalists in Pyongyang, where a contrast was drawn between the South Korean attitude, which favours studying abroad, and that of North Korean Party Secretary Kim Chong-il, who refused the chance to study at the "best university" in an unspecified "socialist country" (almost certainly the Soviet Union), preferring to study "on the basis of the reality of the fatherland in which the Chuche idea was being embodied"'. 